\section{Requiem \\ pour Henrietta}

\section{Simone Gilgenkrantz}

> Plus de cinquante ans après la mort d'Henrietta Lacks, emportée en quelques mois par un cancer du col utérin d'une exceptionnelle gravité, la première lignée continue - les cellules HeLa - reste la plus utilisée dans les laboratoires du monde entier. Elle a contribué à l'étude de nombreuses maladies, poliomyélite, leucémies, maladie de Parkinson, et à la mise au point de nombreux médicaments... Mais son pouvoir de multiplication fut tel qu'elle contamina des centaines d'autres lignées cellulaires un peu partout, y compris en Russie; pendant des décennies, les biologistes ont travaillé sur des cellules à l'origine incertaine et le problème aujourd'hui n'est pas encore résolu. Pourtant, l'histoire des celIules HeLa est d'abord le bouleversant récit des enjeux raciaux et éthiques aux États-Unis durant la seconde moitié du XXe siècle. <

Au cours des cinquante dernières années, quel biologiste ne s'est pas interrogé sur la provenance de cette lignée continue utilisée pour toutes sortes de recherches et appelée cellules HeLa? La dénomination correspondait, disait-on, aux premières syllabes du prénom et du nom de famille d'une femme morte d'un cancer du col de l'utérus. C'était peut-être Helen Lane, Helga Larsen ou même Hedy Lamarr, une actrice d'origine autrichienne qui avait eu ses heures de gloire aux ÉtatsUnis dans les années 1950.

À partir de 1971, un an après la mort de George Gey, éminent biologiste et «père des cellules HeLa», le nom d'Henrietta Lacks était enfin officiellement révélé [1] et diffusé dans la presse scientifique $[2,3]$.

L'histoire d'Henrietta, jeune femme afro-américaine morte sans sépulture,

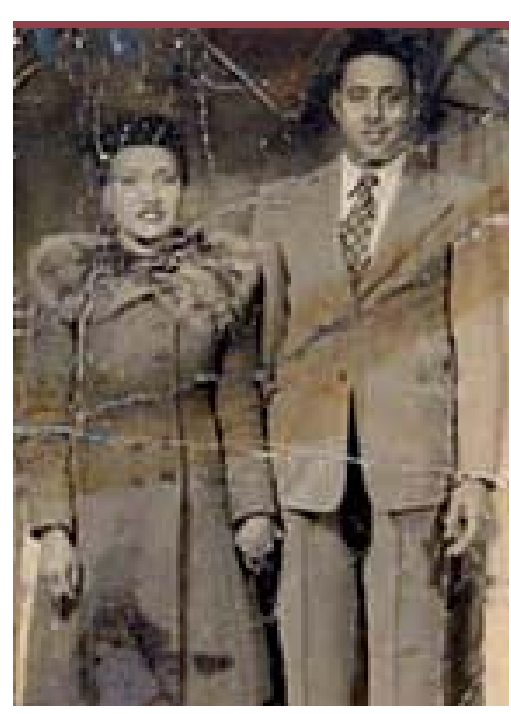

Figure 1. Henrietta et David Lacks vers 1945. (C) 2010, USA Today, a division of Gannet Co. Inc.
S. Gilgenkrantz :

9, rue Basse, 54330 Clérey-sur-Brénon, France. simsimone.gilgenkrantz@gmail.com
Unis ainsi qu'à tous les aspects du développement des biotechnologies en cette deuxième moitié du XXe siècle. Elles ont fasciné, non seulement les scientifiques, mais aussi nombre de poètes, cinéastes, écrivains. Le récent ouvrage de Rebecca Skloot, paru fin 2009, nous donne l'occasion d'analyser ce passé récent en se gardant d'une pensée trop critique, mais afin d'en tirer quelques leçons pour l'avenir.

\section{La vie et la mort d'Henrietta Lacks}

Henrietta (en réalité Loretta Pleasant pour l'état civil) est née en 1920 à Roanoke (Virginie), là même où quatre générations plus tôt ses ancêtres étaient esclaves et travaillaient dans les champs de coton. Sa mère est morte quand elle avait quatre ans en mettant au monde son dixième enfant. Elle est alors placée chez son grand-père maternel Tommy Lacks, à Clover, un hameau où la petite communauté noire cultive du tabac et vit dans un grand dénuement. Tommy a déjà recueilli un autre de ses petits-fils, David Lacks, cousin germain d'Henrietta avec qui elle est élevée. À 20 ans, elle se marie avec lui. Puis, vers 1943 , le couple quitte la Virginie pour s'installer à Turner Station, près de Baltimore (Maryland) où se trouve une importante communauté afro-américaine et où David a trouvé du travail (Figure 1). En février 1951, elle consulte au Johns Hopkins Hospital pour 
métrorragies. Un cancer du col utérin est diagnostiqué et traité par aiguilles de radium, puis par radiothérapie. Mais son état empire rapidement; elle est hospitalisée dans le secteur réservé aux noirs où elle meurt le 4 octobre 1951 à l'âge de 31 ans; l'autopsie montrera un envahissement métastatique généralisé des viscères. Elle laisse 5 enfants dont le dernier a un an et demi.

\section{La naissance des cellules HeLa}

Avant de poser les aiguilles de radium, le médecin prélève un fragment de la tumeur qui est envoyé au laboratoire de culture cellulaire dirigé par George Gey (Figure 2). Depuis des décennies, G. Gey tente de cultiver des cellules cancéreuses in vitro, mais sans succès. Son épouse Margaret, ancienne infirmière en chirurgie supervise le personnel du laboratoire à qui elle a appris à travailler stérilement. Comme elle le fait pour chaque prélèvement, la technicienne, Mary Kubicek, dilacère les tissus et répartit les fragments dans des tubes de culture contenant le milieu conçu par G. Gey, sur lesquels elle écrit HeLa au crayon gras. Elle les place ensuite dans des «rollers » sans se faire d'illusion car aucune tentative de culture n'a réussi jusqu'alors. Après quelques jours, les cellules commencent à proliférer - ce qui était déjà arrivé avec d'autres prélèvements avant qu'ils ne dégénèrent. Mais cette fois, la pousse est stupéfiante. Leur croissance exponentielle nécessite des repiquages incessants. Le 4 octobre, jour de la mort d'Henrietta, George Gey, qui dispose déjà d'une incroyable quantité de cellules, présente à la télévision nationale la première lignée immortalisée dans une émission intitulée «The cancer can be conquered».

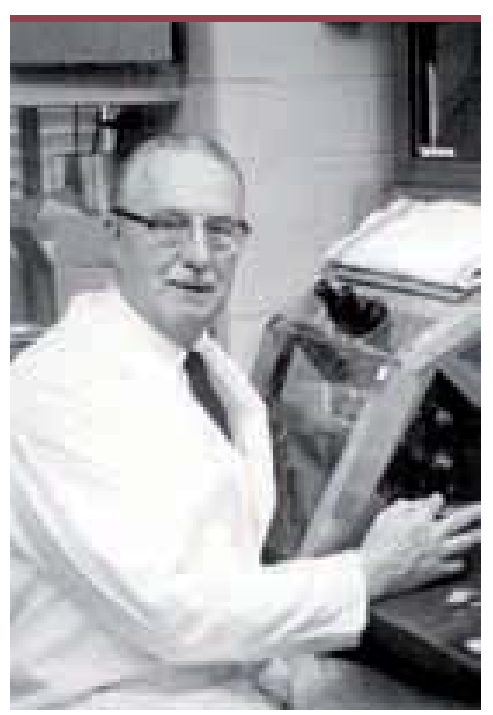

Figure 2. George Gey (1899-1970). (C) From Medical archives of John Hopkins Medical Institute.

\section{George Gey (1899-1970)}

George Otto Gey (Figure 2) s'était intéressé au cancer et aux moyens d'en découvrir la cause. Il avait monté lui-même un laboratoire de culture cellulaire au Johns Hopkins hospital et cherchait à cultiver des cellules cancéreuses in vitro, comme l'avait fait Alexis Carrel avec des celIules de poulet. II avait mis au point des milieux de culture, choisi le matériel de verrerie et inventé la culture mobile en «roller», grande roue tournante (environ 2 tours par heure), pour que le milieu, en mouvement permanent, favorise la prolifération des cellules. Grâce à ce procédé, John Enders put cultiver les virus poliomyélitiques in vitro, ce qui lui valut en 1954 le prix Nobel de physiologie et de médecine. Gey avait aussi installé une caméra $16 \mathrm{~mm}$ sur microscope afin d'observer les mouvements et les divisions cellulaires. II devint directeur du Finney-Howell Cancer Research Laboratory, et fondateur et premier président de la Tissue Culture Association. Bientôt la renommée de cet homme grand et corpulent (il mesurait 1,98 m et pesait aux alentours de $100 \mathrm{~kg}$ ) s'étendit au-delà des frontières. Des chercheurs du monde entier vinrent dans son laboratoire. Quant à la lignée HeLa, il l'envoya à tous ceux qui le souhaitaient. Plus tard, au printemps de l'année 1970, alors qu'il pêche sur les rives du Potomac, il se sent mal. Les examens révèlent un cancer du pancréas. II souhaite alors qu'une lignée GeGe soit établie, mais la laparotomie ayant montré un envahissement inopérable, les chirurgiens décident de ne pas faire de prélèvement.

\section{L’envolée des cellules HeLa}

En 1951 posséder une lignée de cellules cancéreuses était inespéré. Cela prouvait qu'il était possible d'en fabriquer d'autres. Les cellules HeLa tombaient à pic, au moment de la lutte contre la poliomyélite. Quand Jonas Salk commença à produire son vaccin, la première fabrique de production en masse de cellules vivantes HeLa fut montée à l'Institut Tuskegee en Alabama. Entre 1953 et 1955 , les employés (presque tous afro-américains) de cette usine expédièrent plus de 600000 envois [4]. Les cellules HeLa devinrent le support de nombreuses études. Elles furent plusieurs fois envoyées dans l'espace (dans le second satellite, puis dans Discovery XVIII et dans le premier vol habité). Au temps de la guerre froide, elles furent exposées aux radiations atomiques. Enfin elles servirent à la production de vaccins, ou pour tester divers produits, depuis les cosmétiques jusqu'aux anti-viraux. Dès 1960, quand en France Georges Barski réussit à faire fusionner des cellules [5], les cellules HeLa entrèrent dans la formation d'hybrides. Elles contribuèrent au Human Gene mapping. En 1984, Harald zur Hausen découvre une nouvelle souche de papilloma virus : HPV18, responsable de $12 \%$ des cancers du col de l'utérus, ce qui lui valut le prix Nobel en 2008 [6]. HPV18 est retrouvé intégré dans le génome des cellules HeLa, inséré sur le bras long du chromosome 11. Ainsi s'explique la survenue du cancer de Henrietta, mais pas l'extraordinaire pouvoir de multiplication de ces cellules puisque les cancers du col sont habituellement parmi les plus difficiles à cultiver in vitro.

Aujourd'hui encore, les cellules HeLa servent de support à d'innombrables recherches dans tous les domaines de la biologie. Contrairement à ce qu'on pourrait supposer, leur intérêt n'a pas faibli puisque le nombre des publications impliquant les cellules HeLa a quadruplé entre 1980 et 2000 . 


\section{Code de Nuremberg et consentement éclairé}

Les cellules HeLa ont également été témoins et objets de graves manquements à l'éthique biomédicale, qu'il est important ici de rappeler. C'est donc de Tuskegee que des biologistes et des techniciens noirs expédiaient les cellules HeLa vers les laboratoires des États-Unis et du monde entier. Tuskegee, comté de Macon (Alabama), lieu de naissance de Rosa Parks ${ }^{1}$, figure emblématique de la lutte contre la ségrégation. Tuskegee, où fut pratiquée une inacceptable expérimentation humaine à but non thérapeutique pour compléter les connaissances médicales sur l'évolution de la syphilis: la cohorte de 400 hommes noirs syphilitiques inclus dans l'étude a été suivie de 1932 à 1972 sans traitement, pas même lors de la mise sur le marché de la pénicilline en 1942 [7].

En 1956, au Sloan-Kettering Institute de New York, le chef du laboratoire de virologie, Chester Southam ${ }^{2}$, se demandait si les cellules HeLa étaient porteuses d'un virus; si, par inoculation ou injection, elles pouvaient transmettre des cancers. Pour le savoir, il inocula les cellules à des patients atteints de leucémie, de cancer et aussi à des témoins bien portants, les détenus du centre pénitentiaire de l'état d'Ohio... Jusqu'au jour où il s'adressa au Jewish Chronic Disease Hospital de Brooklyn. Là, quelques médecins, ayant en mémoire le procès de Nuremberg et le code qui s'ensuivit, refusèrent avec énergie.

Après de multiples procès, enquêtes, et découvertes du non-respect par de nombreuses institutions des principes éthiques en vigueur [8], le NIH (National Institutes of Health) américain renforça le contrôle d'une stricte observance du «consentement éclairé ».

\section{La Bombe HeLa}

Depuis 1951, suivant l'exemple de G. Gey, de nombreux biologistes avaient établi des lignées continues à partir de tissus cancéreux ou même de tissus normaux (grâce au mécanisme de transformation spontanée). D'où la constitution d'une ATCC (american type culture collection) ainsi que d'un CCCC (cell culture collection committee). II fallait mettre un peu d'ordre dans toutes ces lignées en étudiant leur polymorphisme. En 1966, lors d'une conférence sur ce sujet, Stanley Gartner présente ses résultats. Ils sont tels que par la suite on les appela la HeLa Bomb. Dans les 18 lignées qu'il a étudiées, toutes établies à partir de sujets caucasiens, il trouve un allèle G6PD-A... qui n'existe que dans des populations d'origine africaine; cet allèle est présent, entre autres, dans une lignée réalisée par Leonard Hayflick à partir de cellules provenant du liquide amniotique de sa propre fille et qu'il avait fièrement appelée WISH (pour Wistar Institute et Suzan Hayflick, son épouse, elle aussi caucasienne) [9]. Mais l'idée que les cellules HeLa ont contaminé les autres lignées est tellement invraisemblable qu'elle ne convainc pas. En 1970, Walter NelsonRees, de l'université de Californie, reprend l'authentification des lignées avec de nouvelles techniques (enzymes et chromosomes).

${ }^{1}$ Rosa Parks est cette femme noire qui refusa de céder sa place à un homme blanc dans un autobus.

${ }^{2}$ Il devint par la suite président de l'American Association for cancer research.
Sans ménagement aucun, il dénonce publiquement les auteurs dont les lignées sont contaminées, ce qui remet en question tous les travaux faits à partir de ces cultures [10]. En novembre 1972, une délégation de scientifiques américains en URSS constate avec stupeur que, même dans ce pays, les cellules Hela ont contaminé les lignées: elles avaient réussi à traverser le rideau de fer! Peu à peu, Nelson-Rees, accusateur public, suscite un vif ressentiment dans le monde scientifique. II finit par démissionner en 1981. Actuellement, malgré quelques tentatives pour vérifier les lignées [11], le contrôle n'est pas

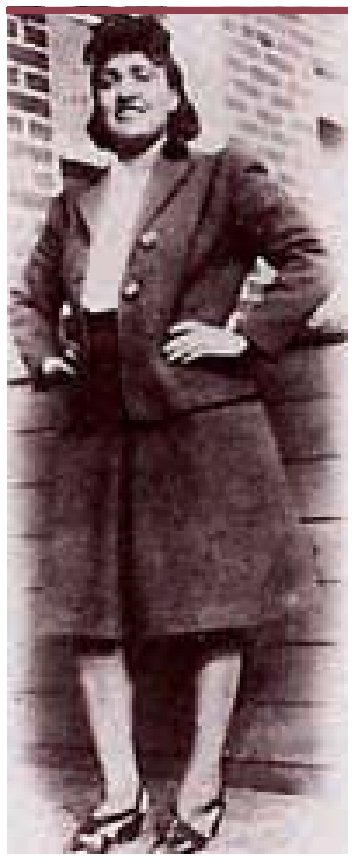

Figure 3. Photo retrouvée dans le dossier médical d'Henrietta Lacks. (C) From Medical archives of John Hopkins Medical Institute. fait de façon systématique [12]. En 2008, on estime qu'environ $20 \%$ des lignées utilisées dans les publications ont subi des contaminations croisées et devraient être refusées par les comités de lecture.

\section{Retour aux sources}

À partir des années 1970, la cartographie des gènes est devenue une priorité des recherches en génétique. Les hybrides somatiques (HeLa-souris entre autres) permettent d'isoler des chromosomes humains et de rechercher la localisation des gènes [13]. Des études familiales sont entreprises et, tout naturellement, il devient important de retrouver la famille d'Henrietta Lacks. Victor McKusick en a besoin, entre autres, pour caractériser la composition du système HLA d'Henrietta. En 1976, 25 ans après sa mort, on retrouve la famille : Day, son mari, et ses enfants Laurence, David $J r$, Déborah et le petit Joe, converti à l'islam en prison et désormais appelé Zakariyya Bari Abdul Rahman. Elsie, atteinte d'épilepsie a été placée très tôt dans l'hospital for negro insane de Crowsville, MA, où elle est décédée vers l'âge de 15 ans. Trois d'entre eux subissent des prélèvements sanguins et le génotype HLA d'Henrietta peut être établi [14]. Mais ignorant tout de cette survie posthume d'Henrietta, ce qu'ils en apprennent alors les terrifie. Aux explications scientifiques que McKusick tente 
de leur apporter se surimprime le souvenir de vieilles légendes des esclaves noirs, enlevés dans la nuit par des médecins vêtus de blanc. Quand Deborah, une fille d'Henrietta prend connaissance du livre de Michael Gold, la lecture du compte rendu d'autopsie qui s'y trouve en détail (the body had been split down and opened wide... grayish white tumor globules...) la laisse anéantie de douleur. Elle y découvre aussi une photo de sa mère qu'elle n'avait jamais vue... (Figure 3). Personne n'avait pensé à informer la famille, personne n'avait demandé un consentement pour la mise en culture des cellules.

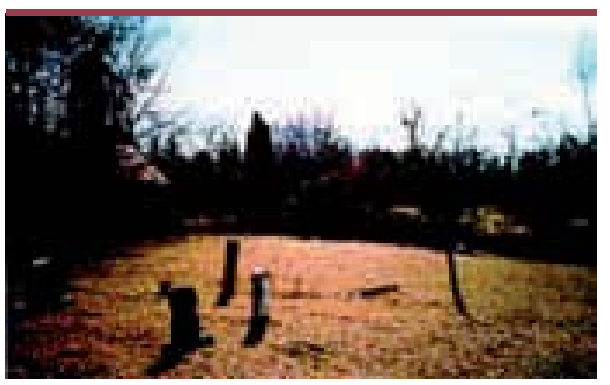

\section{Épilogue}

En 2010 , que reste-til d'Henrietta Lacks? Dans le cimetière dévasté jadis réservé aux noirs, personne ne sait exactement où elle a été enterrée Figure 4. L'ancien cimetière noir de Clover. (Figure 4). La grande maison en rondins où elle avait vécu a disparu, disparu aussi le hameau de Clover détruit par les bulldozers. Du côté de Baltimore, à Turner Station, des commémorations honorent parfois cette héroïne involontaire, ses enfants et leurs descendants: Robert Ehrlich, gouverneur du Maryland, a fait adopter au Congrès une résolution en son honneur : en 1996, la Morehouse School of Medicine d'Atlanta a rassemblé sa famille pour un hommage posthume.

Enfin, un livre intitulé «The immortal life of Henrietta Lacks » vient d'être publié par une journaliste scientifique, Rebecca Skloot, issue d'une classe sociale aisée de la côte pacifique (Figure 5).

Difficile d'être plus éloignée de la famille Lacks, vivant dans une des régions noires les plus déshéritées et les plus dangereuses du pays que cette jeune femme qui n'avait jamais côtoyé de noirs. Non seulement elle a su rassembler l'ensemble des données scientifiques sur les cellules HeLa, mais, en une décennie, avec persévérance, elle a réussi à rencontrer sur place les enfants d'Henrietta, initialement très hostiles. Elle a su tisser avec eux des liens de confiance et d'amitié, de respect réciproque. Elle leur a donné la parole dans son livre. Sous la présidence d'Obama quel beau symbole que ce pont tendu entre les deux Amériques $^{3} ! \diamond$

\section{SUMMARY}

\section{Requiem for Henrietta}

Fifty years after Henrietta Lacks died of aggressive glandular cervical cancer, the first cell line - HeLa cell line - is the workhorse of laboratories everywhere. It helped to produce drugs for numerous diseases, including poliomyelitis, Parkinson's, leukemias. But they are so outrageously robust that they contaminated hundred of other cell lines, as far away as Russia. For decades, biologists worked with contaminated

${ }^{3}$ L'auteur a ouvert une fondation pour les descendants d'Henrietta. Les dons peuvent être envoyés à : http://www.henriettalacksfoundation.org

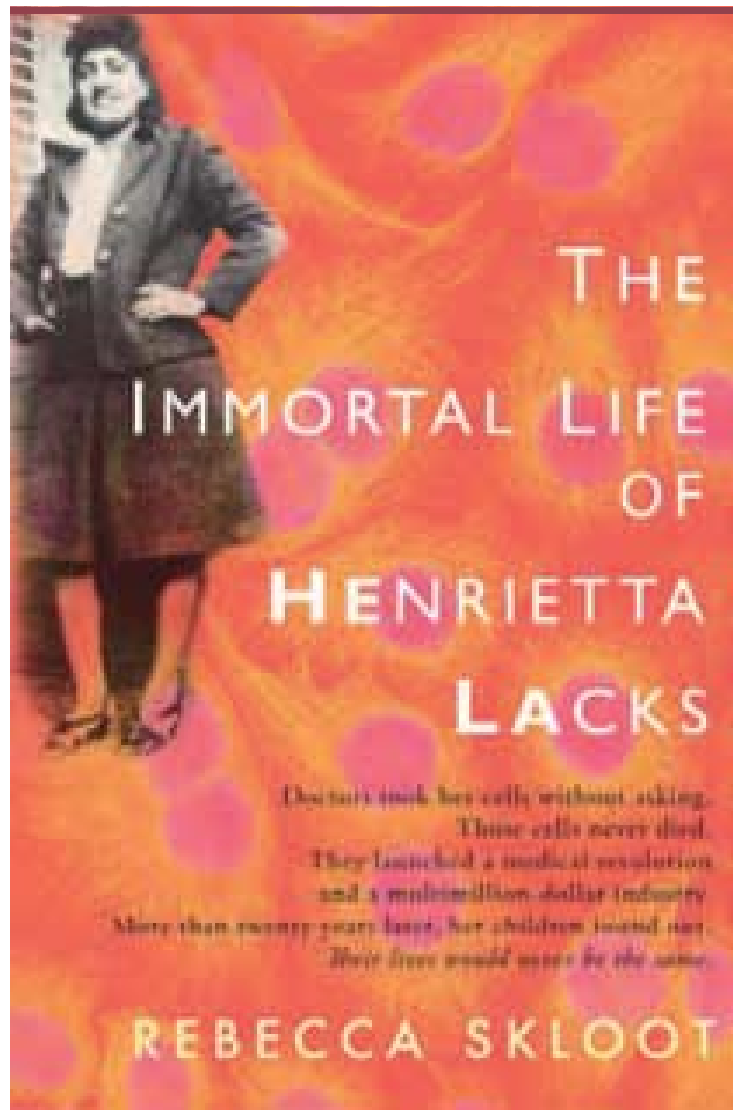

Figure 5. Couverture du livre de Rebecca Skloot.

cell lines and today, the problem is not yet solved. But the story of HeLa cells is also a moving reflection of racial and ethical issues in medicine in the late halftwentieth century in the USA. $\diamond$

\section{CONFLIT D'INTÉRÊTS}

L'auteur déclare n'avoir aucun conflit d'intérêts concernant les données publiées dans cet article.

\section{RÉFÉRENCES}

1. Jones HW Jr, McKusick VA, Harper PS, Wuu KD. George Otto Gey (1899-1970): the HeLa cell and a reappraisal of its origin. Obstet Gynecol 1971; $38: 945-9$.

2. Douglas J. Who was Hela? Nature $1973 ; 242: 144$.

3. Douglas J. HeLa. Nature $1973 ; 242: 543$.

4. Brown RW, Henderson JHM. The mass production and distribution of HeLa cells at Tuskegee institute, 1953-55. J Hist Med Allied Sci 1983; 38 : 415-31.

5. Barski G, Sorieul S, Cornefert F. Production dans des cultures in vitro de deux souches cellulaires en association de cellules de caractère hybride. CR Acad Sci 1960 ; CCLI.

6. Boshart M, Gissmann L, Ikenberg H, et al. A new type of papillomavirus DNA, its presence in genital cancer biopsies and in cell lines derived from cervical cancer. EMBO J $1984 ; 3: 1151-7$.

7. Thomas SB, Quinn SC. The Tuskegee syphilis study, 1932-1972: implications for HIV Education and AIDS risk programs in the black community. Am J Publ Health $1991 ; 81: 1498-505$.

8. Beecher HK. Ethics and clinical research. N Engl J Med 1966 ; 274 : 1354-60.

9. Hayflick L. The establishment of a line (WISH) of human amnion cells in continuous cultivation. Exp Cell Res $1961 ; 23: 14-20$. 


\section{RÉFÉRENCES}

10. Nelson-Rees WA, Daniels DW, Flandemeyer RR. Cross-contamination of cells in culture. Science $1981 ; 212: 446-52$.

11. Nardone RM. Eradication of cross-contaminated cell lines: a call for action. Cell Biol Toxicol $2007 ; 23: 367-72$.

12. Chatterjee R. Cases of mistaken identity. Science 2007; 315 : 930-1.

13. Harris H, Watkins JF, Campbell GL, et al. Mitosis in hybrid cells derived from mouse and man. Nature $1965 ; 207: 606-8$.

14. Hsu SH, Schacter BZ, Delaney NL, et al. Genetic characteristic of the HeLa cell. Science 1976 ; 191 : 392-4.

\section{POUR EN SAVOIR PLUS}

- Marcel Thiry. Prose des cellules HeLa. Toi qui pâlis au nom de Vancouver. Paris : Seghers, 1975.

- Michael Gold. A conspiracy of cells: one woman's immortal legacy and the medical scandal it caused. Albany: State University of New York Press, $1986: 170 \mathrm{p}$

- Rebecca Skloot. The immortal life of Henrietta Lacks. New York: The Crown Publishing Group, 2010 : 384 p.

- Mathias Thery. La vie après la mort d'Henrietta Lacks. Court métrage, 2004.

- Adam Curtis. The way of all flesh. London : BBC, 1997. http://tenpercent. wordpress.com/2009/02/08/adam-curtis-the-way-of-all-flesh/

\section{TIRÉS À PART}

S. Gilgenkrantz

\section{Collection SCIENCE ET BIOMÉDECINE}

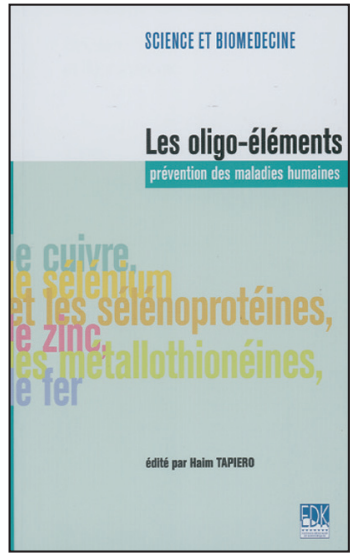

ISBN : 2-84254-107-3 64 pages

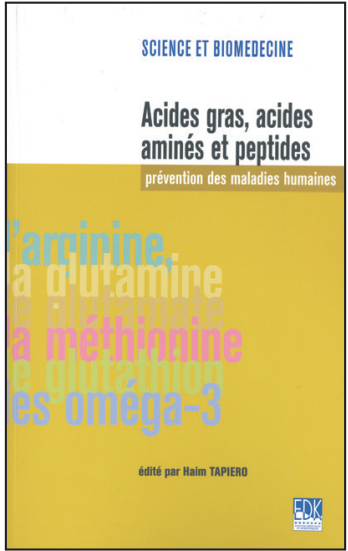

ISBN : 2-84254-108-1 80 pages

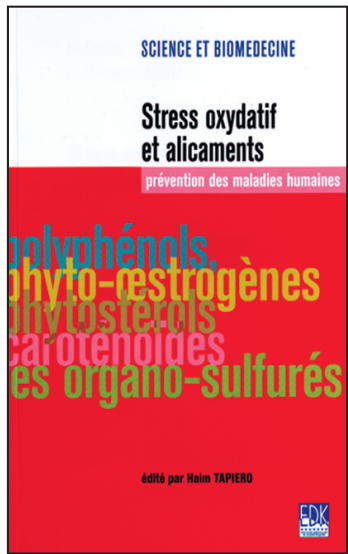

ISBN : 2-84254-111-1 86 pages

\section{Bon de commande}

À retourner à EDK, 2, rue Troyon - 92316 Sèvres Cedex

Tél. : 0155641393 - Fax : 0155641394 - E-mail : edk@edk.fr

NOM : Prénom :.

Adresse :

Code postal : Ville :

Pays :

Fonction :

Je souhaite recevoir l'ouvrage Les oligo-éléments : $10 €+3 €$ de port $=\mathbf{1 3} €$ TTC

Je souhaite recevoir l'ouvrage Acides gras, acides aminés et peptides : $12 €+3 €$ de port $=\mathbf{1 5} €$ TTC

Je souhaite recevoir l'ouvrage Stress oxydatif et alicaments : $14 €+3 €$ de port $=\mathbf{1 7} €$ TTC

$\square$ exemplaire, soit un total de

1 Par chèque, à l'ordre de $\mathbf{E} \mathbf{D} \mathbf{K}$

Par carte bancaire : $\quad \square$ Visa $\square$ Eurocard/Mastercard

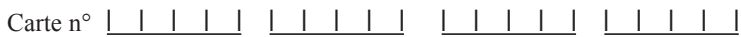

Date d'expiration: $\quad$ । $1 \quad 1 \quad 1 \quad$

Signature :

$\mathrm{N}^{\circ}$ de contrôle au dos de la carte : 